\title{
Selective effects of attentional direction on the startle reflex at different stages of processing
}

\author{
TERRY D. BLUMENTHAL \\ Wake Forest University, Winston-Salem, North Carolina \\ and \\ MAGNE ARVE FLATEN \\ University of Tromsö, Tromsö, Norway
}

\begin{abstract}
In two experiments, we assessed the effects of directed attention on the elicitation and modification of the startle reflex. An acoustic startle stimulus was preceded on some trials by a tone at stimulus onset asynchronies (SOAs) of 120 or $240 \mathrm{msec}$ (Experiment $1, N=26$ ) and 1,200 or 2,400 msec (Experiment $2, N=24$ ). On some trials, following the offset of the startle stimulus, either a tone or a tactile stimulus was presented to the hand (vibration in Experiment 1, airpuff in Experiment 2). On each of four blocks of trials, the subject was given one of the following tasks: Ignore all stimuli, or, when a particular tone prestimulus was presented (high frequency for some subjects, low frequency for others), judge the duration of (1) a tone following the startle stimulus, (2) a tactile stimulus following the startle stimulus, or (3) the startle stimulus itself. The subjects were instructed to ignore all the stimuli when the other tone prestimulus was presented. In the startle-probe-alone conditions, attending to the tactile stimulus increased acoustic startle reactivity (larger startle in Experiment 1, more probable and faster startle in Experiment 2) compared with startle in the ignore condition. Attending to the probe itself did not affect startle amplitude. Responding was similar when subjects attended to either the tone or the probe, suggesting that attention effects were modality specific, but not stimulus specific. Prestimuli at 120- and 240-msec SOAs inhibited startle amplitude in all cases, and this inhibition was more pronounced when attention was directed to any stimulus than in the ignore condition, showing nonspecific attentional effects at short SOAs. At longer SOAs, startle reflexes were inhibited more in the presence of nonsignal prestimuli than signal prestimuli. The increased startle reactivity, which occurred in both experiments when the subjects were required to shift attention from the auditory to the tactile modality, may have been due to greater task demands and, therefore, greater arousal in these conditions.
\end{abstract}

Attentional processing that is underway when a startleeliciting stimulus is presented can influence the startle response to that stimulus (Anthony, 1985; Filion, Dawson, \& Schell, 1994; Graham, 1975). In the present study, we investigated the effects of directing attention toward an acoustic probe, or toward another acoustic stimulus, or toward another sensory modality, while measuring acoustic startle. Attentional effects on the elicitation and the modification of the startle response by a prestimulus were evaluated, with prestimuli presented at either short or long stimulus onset asynchronies (SOAs).

Several studies have shown that directing attention toward prestimuli presented at short SOAs accentuates the reflex inhibition caused by these prestimuli. Acocella and Blumenthal (1990) presented acoustic prestimuli at

\footnotetext{
This research was supported in part by a Norwegian Marshall Fund grant from the Norway America Association and was presented at the meeting of the Society for Psychophysiological Research in RottachEgern, Germany, October 1993. Address correspondence to T. D. Blumenthal, Department of Psychology, Wake Forest University, Box 7778 Reynolda Station, Winston-Salem, NC 27109 (e-mail: blumen@, ac.wfunet.wfu.edu).
}

a 200-msec SOA prior to acoustic startle probes and instructed subjects to press a button when they heard target prestimuli. The subjects showed more startle reflex inhibition when attending to the prestimuli than when they did not. This increase was equal for target and nontarget prestimuli, indicating nonspecific attentional effects. Filion et al. (1994) presented acoustic startle probes at a $120-\mathrm{msec}$ SOA after prestimulus onset, with subjects attending to some of the prestimuli. Filion et al. observed more reflex inhibition for attended than for nonattended prestimuli. Delpezzo and Hoffman (1980) used a visual prestimulus that was presented $150 \mathrm{msec}$ before a tactile, reflex-eliciting stimulus-a tap to the glabella. They found more reflex inhibition when attention was directed toward the prestimulus than when it was not. Harbin and Berg (1986) showed that having subjects attend to a visual task caused more inhibition of tactile startle (airpuff) by an acoustic prestimulus at a 120-msec SOA. Hackley and Graham (1987, Experiment 2) directed subjects' attention toward or away from the ear to which an acoustic prestimulus was delivered and presented tactile reflex-eliciting stimuli at a $63-\mathrm{msec}$ SOA after the prestimulus. They observed more reflex 
inhibition when attention was directed to the ear to which the prestimulus was presented. These five studies suggest that directing attention toward prestimuli at short SOAs causes greater startle inhibition, and that this attentional effect is present whether the prestimuli and startle stimuli are in the same or different sensory modalities.

A theoretical explanation for reflex inhibition at short SOAs that seems to fit these results is protection of preattentive processing of the prestimulus (Graham, 1980). After presentation of the prestimulus, it takes some time for this stimulus to be identified. During this period, processing of other potentially interrupting stimuli, such as a startle stimulus, may be inhibited, thus protecting the processing of the prestimulus. This mechanism seems to be independent of the sensory modalities of the prestimulus and startle probe. The effect on this protective mechanism of directing attention to stimuli in different modalities within the same experiment has never been reported. If protection of preattentive processing is responsible for startle inhibition, this inhibition should be present regardless of the sensory modality to which attention is directed. We tested this hypothesis in Experiment 1 by using prestimuli at short SOAs. Decreased startle reflexes were expected on prestimulus trials in the attention conditions, since prestimulus processing and startle inhibition were expected to be more pronounced.

Attention may also be directed to different stimuli within the same modality. In the present study, attention was directed toward the startle probe, toward another acoustic stimulus (a tone following the startle probe), or toward a tactile stimulus following the startle probe. This allowed us to determine whether the effects of attentional direction were stimulus specific or modality specific, by comparing reflexes when attention was directed to the tone or the tactile stimulus. In the former case, attention is directed to the modality in which the startle probe is presented but to another stimulus, whereas in the latter case attention is directed to another stimulus as well as to another modality. When attention is directed to the probe itself, the stimulus and the modality match, of course. If attention is modality specific, there should be no difference between directing attention to the tone or the probe. If attention is stimulus specific, there should be a difference between these two conditions. A control condition was included, in which the subjects were instructed to ignore all stimuli, and the other three attention conditions were compared with this control condition in order to evaluate the effects of directed attention on startle. On the basis of previous research, we expected reduced startle when attention was directed to the tone or tactile stimulus and increased startle when attention was directed to the probe, compared with the condition in which no attention was directed.

\section{EXPERIMENT 1}

\section{Method \\ Subjects. The subjects were 26 college undergraduates (18-22 years; 4 males, 22 females) at Wake Forest University.}

Apparatus. The startle stimuli were produced by a Coulbourn S81-02 noise generator and gated through a Coulbourn S82-04 audio mixer amplifier. The tone stimuli were produced by two Coulbourn S81-06 signal generators-one set at $200 \mathrm{~Hz}$ and the other at $1000 \mathrm{~Hz}$. These were gated through two Coulbourn audio mixer amplifiers. This amplifier output was sent to a pair of TDH49 headphones. The vibratory stimulus was generated by a Coulbourn S81-02 noise generator that was passed through a Coulbourn S75-38 ECG filter $(1-150 \mathrm{~Hz})$ and gated by a Coulbourn audio mixer amplifier. The output of this amplifier was sent to a Ling 203B Shaker vibrator attached to a $3-\mathrm{cm}^{2}$ contoured contactor. The timing and duration of the stimuli was controlled by a Macintosh SE computer and a MacPacq MP10 computer interface. Auditory stimulus intensity was calibrated with a Quest Electronics 215 sound-level meter, a headphone coupler, and a Fluke $8050 \mathrm{~A}$ digital multimeter, which was used to set the voltage of the output of the Coulbourn amplifiers.

Eyeblink electromyography (EMG) responses were measured with Sensor Medics Ag/AgCl electrodes (4-mm-diam. contactor) filled with Sigma electrode paste. The raw EMG signal was sent to a Coulbourn S75-01 high-gain bioamplifier, where it was amplified and filtered (passing 90-250 Hz). The output of the bioamplifier was sent to a Coulbourn S76-01 contour-following integrator (10-msec constant time), then to a Coulbourn adjustablegain amplifier. The output of the amplifier was digitally sampled every millisecond for $1,000 \mathrm{msec}$, beginning $240 \mathrm{msec}$ before startle-probe onset on all trials, and displayed on the Macintosh SE computer.

Procedure. Before each session, the subject was required to sign an informed consent form and complete a health questionnaire. The skin below the left eye was cleaned with rubbing alcohol and two recording electrodes were attached about $1-1.5 \mathrm{~cm}$ below the pupil and about $1.5-2 \mathrm{~cm}$ below the outer canthus of the left eye. A ground electrode was placed on the medial surface of the left forearm. The subject was asked to remain as still as possible. The right hand was placed on a desk through which the vibrator contact protruded, so that the thenar eminence of the hand rested on the contactor. The headphones were fitted, and examples of each of the five trial types were presented until the subject was sure that he/she could discriminate the low-frequency tone from the high-frequency tone and could feel the vibration on the hand.

A schematic of the stimuli is shown in Figure 1. The startleeliciting stimuli were $100-\mathrm{dB}$ SPL, $80-\mathrm{msec}$ duration, $0.1-\mathrm{msec}$ rise/fall time broadband noises $(20 \mathrm{~Hz}-20 \mathrm{kHz})$. The tone stimuli were $60-\mathrm{dB}$ SPL, $0.1-\mathrm{msec}$ rise/fall time tones, at frequencies of 200 and $1000 \mathrm{~Hz}$. On prestimulus trials, the tones began either 120 or $240 \mathrm{msec}$ before startle stimulus onset and terminated at starthe stimulus onset. At startle stimulus offset, the tone was again presented, ending $660 \mathrm{msec}$ after startle stimulus offset. The tone was not present during the startle stimulus, to avoid interactions between the tone and the startle stimulus. Also, since startle stimulus duration was $80 \mathrm{msec}$, and startle response latency (from stimulus onset) was generally much less than $80 \mathrm{msec}$, the onset of the tone following the startle stimulus was not expected to affect the response to the startle stimulus (Boelhouwer, Teurlings, \& Brunia, 1991). During one stage of the experiment, a vibratory stimulus was presented to the hand at the same time as the tone following the startle stimulus, beginning when the startle probe ended. This vibratory stimulus was a filtered noise $(1-150 \mathrm{~Hz})$, with a $0.1-\mathrm{msec}$ rise/fall time and a duration of $660 \mathrm{msec}$. Prestimuli were presented in four conditions: either 200 - or $1000-\mathrm{Hz}$ tones at either 120 - or $240-\mathrm{msec}$ SOAs. The frequency of the tone following the startle stimulus was always the same as that of the prestimulus on a given trial. In the control condition, only the startle probe was presented, with no preceding or following tone or vibration.

Each subject participated in four blocks of trials, with different attention instructions for each block. The order of the attention 

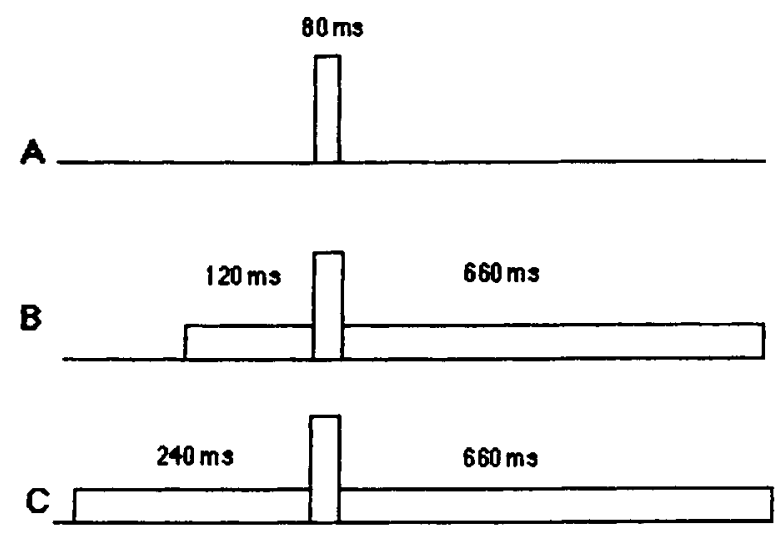

Figure 1. Schematic of stimuli. Control condition (no prestimulus; A); startle probe with 120 -msec duration prestimulus and 660 msec following tone (B); and startle probe with 240 -msec duration prestimulus and $660 \mathrm{msec}$ following tone $(C)$. During one of the four attention blocks, a vibrotactile stimulus was presented to the hand coincidentally with the $660 \mathrm{msec}$ following tone.

blocks was counterbalanced across subjects. In the attention task, the subjects judged whether a target stimulus was longer or shorter than the preceding target stimulus (in fact, all the target stimuli were the same duration, but the subjects did not know this; they were told that the task was quite difficult). The subjects were instructed to call out "longer" or "shorter" on the basis of their judgments. In the four different attention blocks, the target stimulus was the startle probe, the portion of the tone that followed the offset of the startle probe, or the vibration that followed the offset of the startle probe; or, the subject was told to ignore all the stimuli. The vibratory stimulus was presented only during the attention block in which it was the target stimulus, and not in the other three blocks. Also, 12 of the subjects were told to attend only on trials in which the low-frequency-tone prestimulus was presented and to ignore the trials in which the high-frequency-tone prestimulus was presented. Fourteen of the subjects were told to ignore the lowfrequency trials and attend only on the high-frequency trials. This means that the frequency of the tone prestimulus signaled whether a target stimulus was forthcoming. Within each attention block, the subject received 30 trials - six groups of each of the five stimulus conditions (startle probe alone, or startle probe presented with the high- or low-frequency-tone prestimuli at SOAs of 120 or $240 \mathrm{msec}$ ). Intertrial interval ranged from 25 to $35 \mathrm{sec}$.

Data analysis. The amplitude, latency, and probability of the eyeblink response were measured from the integrated EMG sampled by the microcomputer. Only responses with onsets within 20-100 msec after startle probe onset were included, in order to eliminate nonreflexive responses. If the integrated EMG activity surpassed the baseline EMG activity measured for $20 \mathrm{msec}$ after stimulus onset on each trial, a response onset was said to have occurred. Response latency was the time between probe onset and response onset. Response amplitude was the difference between the EMG level at response onset and peak, measured as the maximum value in the window, in arbitrary analog-to-digital units. If the EMG signal during the response window did not deviate from that present during the baseline period before stimulus onset, a failure to respond was recorded. Response probability was calculated as the number of scorable responses that occurred divided by the number of trials on which a response could have been scored, within each stimulus condition.

Data were analyzed in separate multivariate analyses of variance (MANOVAs, BMDP4V) for each dependent variable, using con- servative Greenhouse-Geisser degrees of freedom. Follow-up comparisons were made with pairwise contrasts within a second MANOVA. The required level of significance was .05 in all cases, unless otherwise indicated. Statistical analyses included three within-subjects variables: attention condition (ignore, probe, tone, tactile), interval between tone prestimulus onset and startle probe onset (SOA of 120 or $240 \mathrm{msec}$ ), and whether or not the tone prestimulus was a signal to attend $(200 \mathrm{~Hz}$ for 12 subjects, $1000 \mathrm{~Hz}$ for 14 subjects). In order to test for a general attention effect, data from the ignore condition were also compared with pooled data from the other three attention conditions. One set of analyses was conducted for responding in the control (no prestimulus) condition. Another set of analyses was conducted on startle responses in the presence of prestimuli. When assessing the effect of a prestimulus on startle responding, we subtracted the response to the startle probe in the control (no prestimulus) condition from the response to the startle probe in each prestimulus condition to indicate startle modification. Specifically, startle inhibition is illustrated by reduced response amplitude or probability, or increased response latency. Changes in the opposite direction constitute startle facilitation.

\section{Results}

Responding to the startle probe when it was presented alone (control condition) was analyzed as a function of attention condition (tone, vibration, probe, or nothing). Response probability and latency were not affected by this variable, but response amplitude was $[F(3,75)=$ $3.35, p<.05]$. Amplitude was significantly larger when the subjects attended to the vibration than when they ignored all stimuli $[F(1,25)=4.73, p<.05$; see Table 1$]$. Directing attention to either the tone or the startle probe resulted in an amplitude that was not significantly different from that in the ignore condition $(p=.07$ for the probe vs. ignore comparison; $p=.19$ for the tone vs. ignore comparison). When the results from the attendto-probe and the attend-to-tone conditions were pooled and then compared with those from the ignore condition, a marginal but nonsignificant difference was found $[F(1,25)=4.01, p<.06]$.

For response amplitude on trials in which the startle probe was preceded by a prestimulus, the SOA effect

Table 1

Average Startle Response Amplitude (in Analog-to-Digital Units), Probability, and Latency (in Milliseconds) in Each Attention Condition, for Control Trials Only

\begin{tabular}{|c|c|c|c|c|c|c|}
\hline \multirow[b]{2}{*}{ Condition } & \multicolumn{2}{|c|}{$\begin{array}{c}\text { Startle } \\
\text { Amplitude }\end{array}$} & \multicolumn{2}{|c|}{$\begin{array}{c}\text { Startle } \\
\text { Probability }\end{array}$} & \multicolumn{2}{|c|}{$\begin{array}{c}\text { Startle } \\
\text { Latency }\end{array}$} \\
\hline & $M$ & $S E M^{*}$ & $M$ & $S E M$ & $M$ & $S E M$ \\
\hline \multicolumn{7}{|c|}{ Experiment 1} \\
\hline Ignore & 20.4 & 2.24 & .87 & .036 & 46.1 & .93 \\
\hline Probe & 27.1 & 4.19 & .88 & .035 & 43.5 & 1.45 \\
\hline Tone & 23.1 & 2.57 & .89 & .041 & 45.2 & 1.37 \\
\hline Tactile & 30.9 & 5.42 & .90 & .035 & 44.2 & 1.25 \\
\hline \multicolumn{7}{|c|}{ Experiment 2} \\
\hline Ignore & 33.2 & 2.74 & .77 & .059 & 60.2 & 4.15 \\
\hline Probe & 41.1 & 3.51 & .79 & .052 & 49.0 & 2.06 \\
\hline Tone & 38.6 & 3.87 & .70 & .061 & 52.1 & 1.66 \\
\hline Tactile & 42.5 & 3.62 & .87 & .040 & 50.7 & 2.97 \\
\hline
\end{tabular}

*One standard error of the mean. 
was significant $[F(1,25)=6.20, p<.05]$, but the signal variable and the attention condition were not significant, and none of the interactions were significant. In order to test for a general attention effect, data from the ignore condition were compared with pooled data from the other three attention conditions, including both signal and nonsignal trials. The general attention effect was significant $[F(1,25)=5.90, p<.05]$, as was the general attention $\times$ SOA interaction $[F(1,25)=4.65, p<.05$; see Figure 2]. All prestimuli inhibited startle amplitude, and this inhibition was more pronounced when the subjects attended to a stimulus than when they ignored all stimuli. Further, the prestimuli at the longer SOA caused more inhibition than those at the shorter SOA, but only when the subject attended to a stimulus. No SOA difference was found in the ignore condition.

For modification of response probability, the SOA effect was significant $[F(1,25)=12.48, p<.01]$, as was the signal variable $[F(1,25)=4.32, p<.05$; see Figure 3]. Response probability was inhibited to a greater degree when prestimulus SOA was $240 \mathrm{msec}$ than when it was $120 \mathrm{msec}$, and was more inhibited when the prestimulus signaled that a target would be presented than when the prestimulus signaled that a target would not be presented. No effect of attention condition and none of the interactions reached significance. In order to test for a general attention effect, data from the ignore condition were compared with pooled data from the other three attention conditions. No significant general attention effect was found $(p=.08)$.

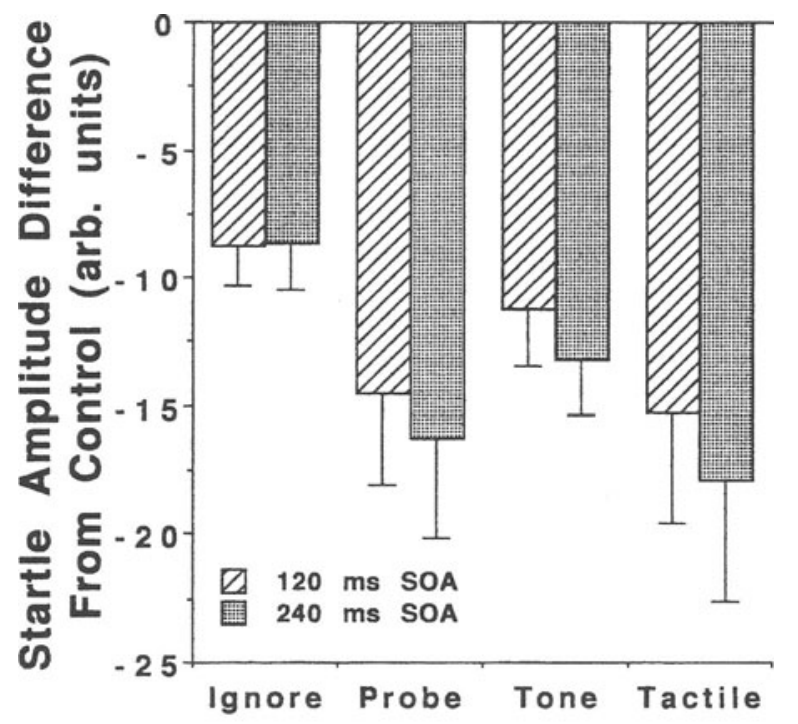

\section{Attention Condition}

Figure 2. Startle reflex amplitude modification (prestimulus condition minus control condition) as a function of attention condition and stimulus onset asynchrony (SOA; lines represent one standard error of the mean). Note-arb, arbitrary.

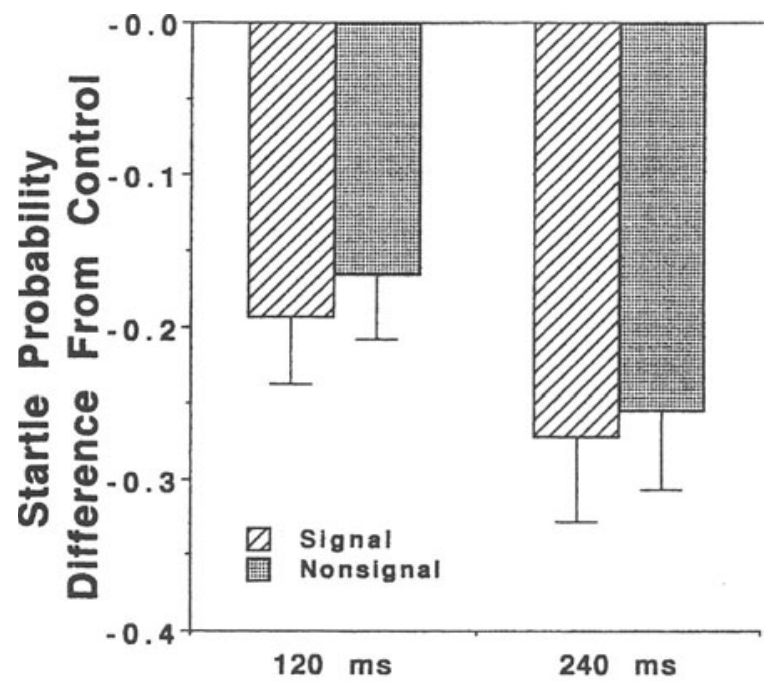

Prestimulus SOA

Figure 3. Startle reflex probability modification (prestimulus condition minus control condition) as a function of signal condition and stimulus onset asynchrony (SOA; lines represent one standard error of the mean).

For modification of response latency, none of the main effects of signal, SOA, or attention condition were significant, but the signal $\times$ prestimulus SOA interaction was significant $[F(1,25)=6.42, p<.05$; see Figure 4]. At a $120-\mathrm{msec} \mathrm{SOA}$, signal prestimuli caused more facilitation of latency than did nonsignal prestimuli, and the opposite was true for prestimuli at the $240-\mathrm{msec}$ SOA. In order to test for a general attention effect, data from the ignore condition were compared with pooled data from the other three attention conditions. No significant general attention effect was found $(p=.09)$.

\section{Discussion}

When compared with the ignore condition, the control startle responses were significantly larger when the subjects attended to a stimulus in a modality other than that in which the startle probe was presented, but not when they attended to the startle probe itself. However, attending to any stimulus in the auditory modality (probe or tone) resulted in responses that were marginally larger than those in the ignore condition $(p<.06)$. These findings do not support previous research in which smaller startle responses were found when attention was directed away from the startle modality, but they marginally support research that has shown larger responses when attention was directed toward the startle modality (Bohlin \& Graham, 1977; Bohlin, Graham, Silverstein, \& Hackley, 1981; Silverstein, Graham, \& Bohlin, 1981). The difficulty of the task in the attend-to-tactile condition may have contributed to increased startle in this condition, as will be discussed in the General Discussion. 


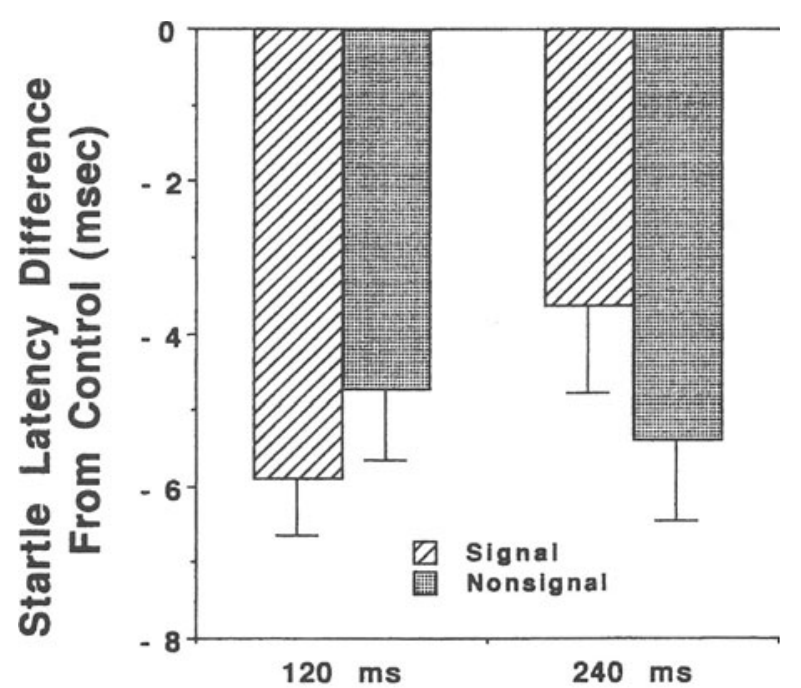

Prestimulus SOA

Figure 4. Startle reflex latency modification (prestimulus condition minus control condition) as a function of signal condition and stimulus onset asynchrony (SOA; lines represent one standard error of the mean).

The present results also showed more inhibition of startle response amplitude when attention was directed to any stimulus than when subjects were instructed to ignore all stimuli. This was not affected by the stimulus that was attended to, indicating a nonspecific attention effect. This supports earlier findings (Acocella \& Blumenthal, 1990; Filion et al., 1994) that directing attention has effects on startle at early stages of auditory processing. However, startle inhibition was equivalent when attention was directed away from the modality of the probe and when it was directed to the probe itself. If startle inhibition can be explained by the protection of preattentive processing, then it appears that attentional demands strengthen this protection for all stimuli at short SOAs, regardless of the modality or stimulus to which the attention is directed.

These data also illustrate an interesting dissociation of prestimulus effects on response amplitude and response latency, in that the same prestimuli that inhibited response amplitude facilitated response latency. This is further evidence for the hypothesis that these two response measures may be determined by separate neurological mechanisms (Britt \& Blumenthal, 1993; Graham \& Murray, 1977).

\section{EXPERIMENT 2}

At SOAs of $2 \mathrm{sec}$ or more, prestimuli do not have a reliable inhibitory effect on startle. Previous research has suggested that directing attention to long-SOA prestimuli can cause the inhibition of startle if attention is directed away from the modality in which the startle probe occurs, or facilitation of startle when attention is di- rected toward the startle probe modality (Bohlin \& Graham, 1977; Bohlin et al., 1981; Filion, Dawson, \& Schell, 1993; Silverstein et al., 1981). Bohlin et al. used an SOA of $2 \mathrm{sec}$ between prestimuli and acoustic startle probes in three different conditions. In the first condition, attention was directed to the startle probe by instructing the subjects to judge the duration of the probes. Startle was larger when attention was directed to the probes than when it was not. In the second condition, novel prestimuli that elicited generalized orienting responses were introduced prior to the probes, and startle was again facilitated, showing that orienting increased sensory intake, thus increasing the startle reflex response. In a third condition, attention was directed to the prestimuli. There were no differences between reflexes elicited after attended to and ignored prestimuli, even when the prestimuli and startle probe were presented in the same sensory modality.

Anthony and Graham (1985) presented dull and interesting prestimuli in the visual and auditory modalities and crossed these with visual and auditory startle probes presented $4 \mathrm{sec}$ after prestimulus onset. It was hypothesized that attention would be directed more to the interesting prestimuli and less to the dull prestimuli. Anthony and Graham thus compared the effects of two levels of attention and the matching or mismatching of sensory modality for the prestimuli and the startle probe. The results showed that the interesting and dull prestimuli both elicited orienting, as indexed by heart rate deceleration. Startle magnitudes were increased when the modality of the prestimulus matched that of the startle probe and the prestimulus was an interesting one. There was a tendency, although nonsignificant, for decreased startle reflexes when attention was directed to an interesting prestimulus that did not match the modality of the startle probe. This indicates that attention to the modality of the startle probe increases startle and, less strongly, that attention to a different modality decreases startle.

Filion et al. (1993) had subjects attend to or ignore acoustic prepulses presented at SOAs of $60,120,240$, and $2,000 \mathrm{msec}$ before acoustic startle stimuli. Attended prepulses resulted in greater inhibition of startle at a $120-\mathrm{msec}$ SOA as well as greater facilitation of startle at a 2,000-msec SOA.

Experiment 2 was performed to further investigate the effects of the time course of attentional processes on startle. Attention was directed as in Experiment 1, and the SOA between prestimulus and probe onset was increased to 1,200 and $2,400 \mathrm{msec}$. On the basis of the findings of Anthony and Graham (1985), Bohlin et al. (1981), and Filion et al. (1993), it was predicted that startle would be facilitated when attention was directed to the modality of the probe, and inhibited when it was directed away from the modality of the probe.

\section{Method}

Subjects. The subjects were 24 university students (19-31 years old; 9 males, 15 females) at the University of Tromsö. 
Apparatus. The experiment took place in a Tegner chamber that was electrically and sound shielded. Control of the experiment and response sampling was done via a Keithley 575 interface in ASYST 3.1 run on an ALR 486 PC. The startle stimuli were produced by a Coulbourn S81-02 noise generator. The output was passed to a Coulbourn S77-06 multiplier/divider and then to a Coulbourn S78-03 linear summing amplifier. The output was sent to an NAD Electronics 3225PE stereo amplifier and then to a pair of Sennhauser headphones. The tone stimuli were generated by using the ASYST software, which activated a Coulbourn S24-05 voltage-controlled oscillator, the output of which was sent to a Coulbourn rise/fall gate. The signal then entered a Coulbourn linear summing amplifier, then the NAD amplifier, and finally the headphones. The airpuff was delivered through a plastic tube that had an internal diameter of $1.5 \mathrm{~mm}$ and a length of $2.5 \mathrm{~m}$ from the solenoid valve to the nozzle. The tube was taped to the subject's right index finger, and the airpuff was directed to the thenar eminence. The valves controlling the airpuff were placed outside the chamber so that the subject could not hear their operation. The equipment for presentation of airpuffs is described in more detail by Flaten, Vaksdal, and Hugdahl (1989).

Eyeblink EMG responses were recorded from the left orbicularis oculi with $\mathrm{Ag} / \mathrm{AgCl}$ Beckman miniature electrodes (4-mmdiam. contactor) filled with TECA conducting paste. The EMG signal was amplified and filtered (passing 90-250 Hz) by a Coulbourn 75-01 bioamplifier. The signal was then integrated by a Coulbourn S76-01 contour-following integrator (10-msec time constant), and the output was sent to the computer via the Keithley interface. Sampling on each trial began $200 \mathrm{msec}$ prior to onset of the first stimulus and continued to the end of the probe on probe-alone trials, or to the end of the following tone on prestimulus trials. The sampling rate was $100 \mathrm{~Hz}$ prior to onset of the first stimulus, and $1000 \mathrm{~Hz}$ after onset of the stimulus.

Procedure. The subject was seated in a comfortable armchair and was instructed not to close his/her eyes. Before electrode placement, the skin was cleaned with pads containing alcohol and pimpstone. Then the EMG electrodes were attached about 1$1.5 \mathrm{~cm}$ below the pupil and about $1.5-2 \mathrm{~cm}$ below the outer canthus of the left eye. A ground electrode was placed on the forehead. Finally, the airpuff cable and earphones were fitted.

The startle-eliciting stimuli were $90-\mathrm{dB}$ SPL, 80 -msec duration, 0.1 -msec rise/fall time broadband noise bursts $(20 \mathrm{~Hz}-20 \mathrm{kHz})$. The tone stimuli had frequencies of 200 or $1000 \mathrm{~Hz}$, with intensities of 65 and $68 \mathrm{~dB}$ SPL, respectively, and rise times of $20 \mathrm{msec}$. On prestimulus trials, the tones began either 1,200 or $2,400 \mathrm{msec}$ before startle stimulus onset and terminated $660 \mathrm{msec}$ after startle stimulus offset. Unlike Experiment 1, the tones were on during the startle stimulus. The airpuff presented to the hand had an intensity of $4 \mathrm{psi}$, as indicated at the pressure regulator. It had a duration of $660 \mathrm{msec}$, beginning when the startle stimulus terminated.

The experimental procedure was similar to that of Experiment 1 ; it consisted of four phases. The subjects were instructed to attend to the startle probe, the portion of the tone that followed the offset of the startle probe, or the airpuff that followed the offset of the startle probe; or, they were told to ignore all the stimuli. In the attention task, the subjects judged whether the target stimulus was longer or shorter than the preceding target stimulus (in fact, all the target stimuli were the same duration). The subjects were instructed to call out "longer" or "shorter" on the basis of their judgments. The airpuff stimulus was presented only during the attention block in which it was the target stimulus, and not in the other three blocks. Further, 12 of the subjects were told to attend only on trials in which the low-frequency-tone prestimulus was presented, and to ignore the trials in which the highfrequency-tone prestimulus was presented. Twelve of the subjects were told to ignore low-frequency trials and attend only on highfrequency trials. This means that the frequency of the tone pre- stimulus signaled whether a target stimulus was forthcoming. Within each attention block, the subjects received 30 trials-six groups of each of the five stimulus conditions (startle probe alone, or startle probe presented with the high- or low-frequency tones at SOAs of 1,200 or $2,400 \mathrm{msec}$ ). Intertrial interval ranged from 25 to $35 \mathrm{sec}$.

Data analysis. Startle reflexes were recorded in the 20 - to $120-\mathrm{msec}$ interval after startle stimulus onset. To count as a startle reflex, the integrated EMG voltage had to increase relative to baseline, which was computed as the mean EMG output for the $200 \mathrm{msec}$ prior to stimulus onset. Response latency was the time between probe onset and response onset. Response amplitude was the difference between the EMG level at response onset and peak, measured as the maximum value in the window, in arbitrary analog-to-digital units. If the EMG signal during the response window did not deviate from that present during the baseline period before stimulus onset, a failure to respond was recorded. Response probability was calculated as the number of scorable responses that occurred divided by the number of trials on which a response could have been scored, within each stimulus condition. The data were analyzed by MANOVA, using the CSS (Statsoft) statistical program. Follow-up tests were performed by contrast analysis. An alpha level of .05 was chosen.

Statistical analyses included three within-subjects variables: attention condition (ignore, probe, tone, tactile), interval between tone prestimulus onset and startle probe onset (SOA of 1,200 or $2,400 \mathrm{msec}$ ), and whether or not the tone prestimulus was a signal to attend ( $200 \mathrm{~Hz}$ for 12 subjects; $1000 \mathrm{~Hz}$ for 12 subjects). One set of analyses was conducted for responding in the control (no prestimulus) condition. Another set of analyses was conducted on the difference between startle responses in the control condition and those on prestimulus trials.

\section{Results}

Responding to the startle probe when it was presented alone (control condition) was analyzed as a function of attention condition (tone, vibration, probe, or nothing). Response amplitude was not affected, but control responses were more frequent in the block in which attention was directed to the somatosensory modality than when the subjects were ignoring all stimuli $[F(1,23)=4.49, p<.05$; see Table 1]. Response latency was significantly shorter on control trials in the blocks in which attention was directed to the probe itself or to the somatosensory modality than when attention was not directed to any stimulus $[F(1,23)=8.33$, $p<.01$, and $F(1,23)=5.30, p<.05$, respectively; see Table 1]. Responding in the other attention conditions was not significantly different from that in the ignore condition.

For response amplitude on trials in which the startle probe was preceded by a prestimulus, there was a significant main effect of signal versus nonsignal prestimuli $[F(1,23)=6.33, p<.05]$. This was due to less inhibition in the presence of the signal prestimuli than in the presence of the nonsignal prestimuli (see Figure 5). Also, there was a significant main effect of SOA $[F(1,23)=7.48, p<.05]$, which was due to less inhibition at the $2,400-\mathrm{msec}$ SOA than at the $1,200-\mathrm{msec}$ SOA. No other main effects or interactions were significant for response amplitude, and there were no significant effects on startle probability or latency. 


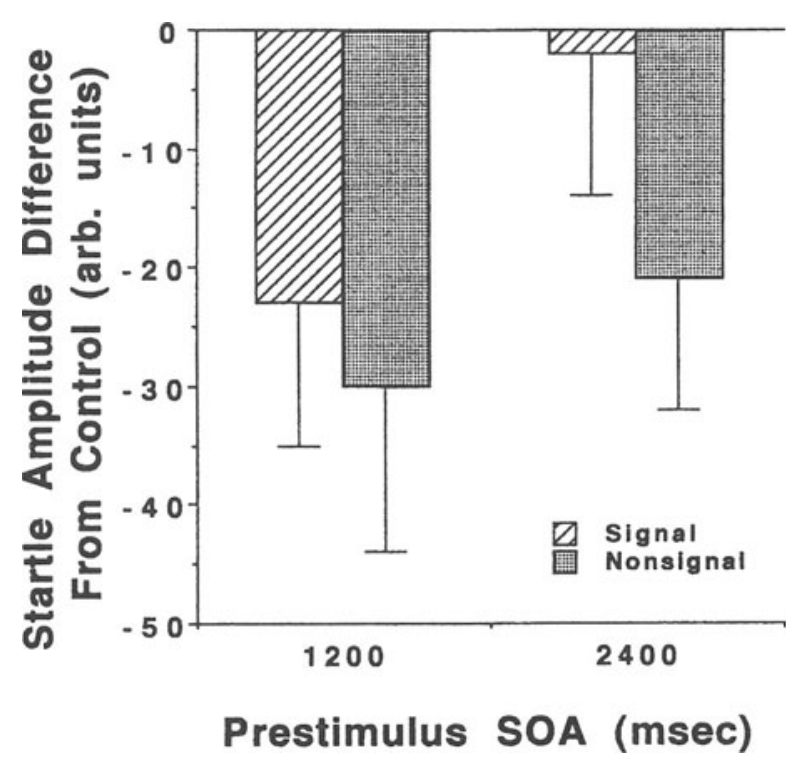

Figure 5. Startle reflex amplitude modification (prestimulus condition minus control condition) as a function of signal condition and stimulus onset asynchrony (SOA) in Experiment 2 (lines represent one standard error of the mean). Note-arb, arbitrary.

\section{Discussion}

The startle probability data in the control condition indicate maximal reactivity to the startle probe during the block in which attention was directed to the somatosensory stimulus - that is, a modality different from the one in which the startle probe was presented. This finding is similar to the response amplitude finding of Experiment 1 . Decreased response latencies (i.e., reflex facilitation) were observed when attention was directed to the somatosensory modality and to the probe itself. The former finding also supports the amplitude data of Experiment 1 . Attention effects on response amplitude and probability in this experiment appear to be modality specific, and not stimulus specific, since there was no difference between the attention-to-tone and attention-toprobe conditions. Significantly larger reflex amplitudes were seen in the presence of the signal prestimuli than in the presence of the nonsignal prestimuli. This illustrates the fact that prestimulus effects at long SOAs can be specific to the signal stimulus, unlike those at short SOAs, such as in Experiment 1, where a nonspecific attentional effect was found.

\section{GENERAL DISCUSSION}

Two levels of attentional specificity are demonstrated by the results of these two experiments. First, differences between modality-specific and stimulus-specific attention were tested with the attention condition variable. If the effects of attending to the tactile stimuli were different from those of attending to the acoustic stimuli, then modality-specific attention is supported. If the effects of attending to the probe were different from those of attending to the tone, then stimulus-specific attention effects within a modality were supported. For the elicitation of startle in control conditions, responding was not significantly different when the subjects were told to attend to the probe or the tone; this argues against stimulus-specific attention. Responding was significantly different when attending to tactile versus acoustic stimuli, providing support for modality-specific attention. However, this support was present only for response amplitude in Experiment 1 and response probability and latency in Experiment 2 . These differences may have been due to the fact that the startle probe stimulus intensity in Experiment 2 was $10 \mathrm{~dB}$ lower than that in Experiment 1. Support for modality-specific attention was also provided by the effect of prepulses on response amplitude in Experiment 1. Prepulses were more effective when the subjects attended to tactile target stimuli than when they attended to acoustic target stimuli.

Another level at which attentional effects can be evaluated is shown by the signal variable in the present experiments. When this variable is significant, the signal value of the prestimulus influences its effectiveness as a modifier of the startle reflex. In Experiment 1, the signal prestimuli were more effective modifiers of response probability at both SOAs and of response latency at a $120-\mathrm{msec}$ SOA. This supports the findings of Acocella and Blumenthal (1990) and Filion et al. (1994), who found that signal prestimuli were more effective modifiers of startle than were nonsignal prestimuli. At longer lead times, inhibition of response amplitude was more pronounced for nonsignal prestimuli than for signal prestimuli. This is interesting when one considers that the usual findings with long SOAs are either no effect on startle amplitude or facilitation of startle amplitude (Anthony, 1985).

The effects of attention direction and prestimulus signal value on startle response elicitation and modification differed for the three measures of startle in these experiments. This provides further evidence for the hypothesis that these measures of startle responding are determined by partially independent, underlying mechanisms (Blumenthal \& Berg, 1986; Graham \& Murray, 1977).

The tendency in the control (no prestimulus) conditions toward increased startle reflex reactivity when attention was directed away from the modality containing the startle probe could also be explained by the relative difficulty of the attention tasks, which were slightly different in each of the four attention conditions. The descriptions of the tasks were formulated so that they would be as similar as possible - all of the tasks were to judge the duration of stimuli that occurred immediately after the probe, or the duration of the probe itself, with the prestimulus acting as a differential warning stimulus. However, the difficulty of the task in the attend-to-tactile condition may have contributed to increased startle in this condition. The prestimulus in our experiments was, in all conditions, a tone that was hypothesized to direct attention. The tone may have occupied attentional resources, and the subject then had to ignore the tone in 
addition to attending to the probe or tactile stimulus. Since the tactile stimulus was in a different modality, this would be the more difficult of the tasks, and the contribution of increased arousal may have made the subjects more responsive to startle stimuli in this condition in both of our experiments. This arousal effect appears to have influenced reactivity to the startle stimuli, but not to the prestimuli. This seems reasonable, given the large intensity differences between the prestimuli and startle stimuli. Other researchers have also found that increased task demands can lead to increased startle reactivity (Cuthbert, Bradley, McManis, Bruner, \& Lang, 1993; van Eekelen, Garner, Berg, \& Boswell, 1993).

Skinner and Yingling (1977) put forth a theory of selective attention that involves the inhibitory effect of the reticularis thalamic nucleus (RTN) on sensory subcortical pathways that pass through the thalamus toward the cortex. The normal state in this system is inhibition by the RTN on all sensory pathways. Selective attention toward a stimulus or modality means disinhibition of the relevant pathway by the RTN. In our attention-to-tactile condition, the RTN would first have to disinhibit the auditory pathway and, subsequently, if the auditory prestimulus was a signal prestimulus, disinhibit the somatosensory pathway. Thus, both pathways could be open simultaneously. How this should increase eyeblink reflexes is not clear. Findings by Garner, Berg, and Shortley (1992) may indicate a solution to this anomaly, however. They observed eyeblink reflexes elicited by airpuffs to the thenar eminence on the hand, called the palmo-orbicularis oculi reflex. The airpuff used in the present Experiment 2 was indeed directed to the thenar eminence, but it was presented after the probe and made no direct contribution to the elicitation of the startle reflex. However, by directing attention to the palm of the hand, we may have increased the reflex response that is elicited by another stimulus - the acoustic probe. This could mean that directing attention to the palm would increase the sensory input from this location and, consequently, the activity of the facial nucleus might be facilitated. When the probe is presented and activates the motoneurons that are already facilitated, the reflex is increased.

If this interpretation is correct, it follows that reflex facilitation should be observed only when attention is directed to the hand or other bodily locations contributing to the eyeblink reflex. If attention is directed to other locations that do not contribute to the eyeblink reflex, then reflex inhibition may be observed (Bohlin \& Graham, 1977). However, Bauer (1982) and Putnam and Meiss $(1980,1981)$ presented a tactile stimulus to the hand or fingers, prior to an acoustic probe, thus directing attention to the somatosensory modality. Contrary to our findings, they observed reflex inhibition. One difference between their procedure and ours is that we directed attention by our instructions to judge the duration of the tactile stimulus presented after the probe, whereas they presented the tactile stimulus prior to the probe. Thus, the temporal relations between the "target stimulus" and probe were different in the two studies.

In summary, acoustic startle reactivity in the probealone conditions of the present experiments was greater when the subjects attended to the tactile stimuli than when they ignored all stimuli. Attending to the probe itself did not affect startle amplitude. Responding was similar when subjects attended to either the tone or the probe, suggesting that attention effects were modality specific, but not stimulus specific. Prestimuli at 120 and 240-msec SOAs inhibited startle amplitude in all cases. This inhibition was more pronounced in the conditions in which attention was directed to any stimulus than in the ignore conditions, showing nonspecific attentional effects at short SOAs. The increased startle reactivity that occurred in both experiments when the subjects were required to shift attention from the auditory to the tactile modality may have been due to greater task demands and, therefore, greater arousal in these conditions.

\section{REFERENCES}

Acocella, C. M., \& Blumenthal, T. D. (1990). Directed attention influences the modification of startle reflex probability. Psychological Reports, 66, 275-285.

ANTHONY, B. J. (1985). In the blink of an eye: Implications of reflex modification for information processing. In P. K. Ackles, J. R. Jennings, \& M. G. H. Coles (Eds.), Advances in psychophysiology (Vol. 1, pp. 168-218). Greenwich, CT: JAI Press.

Anthony, B. J., \& GRAHAM, F. K. (1985). Blink reflex modification by selective attention: Evidence for the modulation of 'automatic' processing. Biological Psychology, 20, 43-59.

BAUER, L. O. (1982). Preparatory modification of the polysynaptic eyeblink reflex. Psychophysiology, 19, 550. (Abstract)

Blumenthal, T. D., \& BERG, W. K. (1986). Stimulus rise time, intensity, and bandwidth effects on acoustic startle amplitude and probability. Psychophysiology, 23, 635-641.

Boelhouwer, A. J. W., Teurlings, R. F. M. A., \& Brunia, C. H. M. (1991). The effect of an acoustic warning stimulus upon the electrically elicited blink reflex in humans. Psychophysiology, 28, 133139.

Bohlin, G., \& Graham, F. K. (1977). Cardiac deceleration and reflex blink facilitation. Psychophysiology, 14, 423-430.

Bohlin, G., Graham, F. K., Silverstein, L. D., \& Hackley, S. A. (1981). Cardiac orienting and startle blink modification in novel and signal situations. Psychophysiology, 18, 603-611.

BritT, T. W., \& Blumenthal, T. D. (1993). Social anxiety and latency of response to startle stimuli. Journal of Research in Personality, 27, $1-14$.

Cuthbert, B., Bradley, M., McManis, M., Bruner, R., \& Lang, P. (1993). Probe type and task in picture perception. Psychophysiology, 30, \$22. (Abstract)

Delpezzo, E. M., \& Hoffman, H. S. (1980). Attentional factors in the inhibition of a reflex by a visual stimulus. Science, 210, 673-674.

Filion, D. L., Dawson, M. E., \& Schell, A. M. (1993). Modification of the acoustic startle-reflex eyeblink: A tool for investigating early and late attentional processes. Biological Psychology, 35, 185-200.

Filion, D. L., Dawson, M. E., \& Schell, A. M. (1994). Probing the orienting response with startle modification and secondary reaction time. Psychophysiology, 31, 68-78.

Flaten, M. A., Vaksdal, A., \& Hugdahl, K. (1989). An IBM-PC and Commodore 64 microcomputer-based system for elicitation and recording of eyeblink reflexes. Biological Psychology, 29, 291-298.

Garner, E. E., BerG, W. K., \& Shortley, B. M. (1992). Blinks at your fingertips: Part II. The palmo-orbicularis oculi connection. Psychophysiology, 29, S33. (Abstract) 
Graham, F. K. (1975). The more or less startling effects of weak prestimulation. Psychophysiology, 12, 238-248.

Graham, F. K. (1980). Control of reflex blink excitability. In L. H. Hicks, R. F. Thompson, \& V. B. Shvyrkov (Eds.), Neural mechanisms of goal-directed behavior and learning (pp. 511-519). New York: Academic Press.

Graham, F. K., \& Murray, G. M. (1977). Discordant effects of weak prestimulation on magnitude and latency of the reflex blink. Physiological Psychology, 15, 108-114.

HaCKLEY, S. A., \& GRAHAM, F. K. (1987). Effects of attending selectively to the spatial position of reflex-eliciting and reflex-modulating stimuli. Journal of Experimental Psychology: Human Perception \& Performance, 13, $411-424$.

HARBIN, T. J., \& BERG, K. W. (1986). The effects of age and attention upon reflex inhibition. Biological Psychology, 22, 81-94.

Putnam, L. A., \& MeIss, D. A. (1980). Reflex inhibition during HR deceleration: Selective attention of motor interference? Psychophysiology, 17, 324. (Abstract)
Putnam, L. A., \& Meiss, D. A. (1981). Reflex blink facilitation during cardiac deceleration: Sensory or motor set? Psychophysiology, 18, 173. (Abstract)

Silverstein, L. D., Graham, F. K., \& Bohlin, G. (1981). Selective attention effects on the reflex blink. Psychophysiology, 18, 240247.

SkinNer, J. E., \& Yingling, C. D. (1977). Central gating mechanisms that regulate event-related potentials and behavior. In J. E. Desmedt (Ed.), Attention, voluntary contraction and slow potential shifts (pp. 30-69). Basel: Karger.

van Eekelen, A. P. J., Garner, E. E., Berg, W. K., \& Boswell, A. E. (1993). Selective facilitation and inhibition of startle occurs late in warning interval. Psychophysiology, 30, S67. (Abstract)

(Manuscript received December 6, 1993; revision accepted for publication June 10, 1994.) 